Bulletin d'Histoire Contemporaine de

I'Espagne

$54 \mid 2020$

Les espaces du politique dans l'Espagne du Trienio liberal (1820-1823)

\title{
Sara HIDALGO GARCÍA DE ORELLÁN, Los resistentes. Relato socialista sobre la violencia de ETA (1984-2011)
}

\section{Gaizka FERNÁNDEZ SOLDEVILLA}

\section{(2) OpenEdition}

\section{Journals}

\section{Edición electrónica}

URL: http://journals.openedition.org/bhce/3222

DOI: $10.4000 /$ bhce.3222

ISSN: 1968-3723

\section{Editor}

Presses Universitaires de Provence

Edición impresa

Fecha de publicación: 1 enero 2020

ISSN: 0987-4135

\section{Referencia electrónica}

Gaizka FERNÁNDEZ SOLDEVILLA, « Sara HIDALGO GARCÍA DE ORELLÁN, Los resistentes. Relato socialista sobre la violencia de ETA (1984-2011) », Bulletin d'Histoire Contemporaine de l'Espagne [En línea], 54 | 2020, Publicado el 01 julio 2020, consultado el 04 enero 2021. URL : http://

journals.openedition.org/bhce/3222 ; DOI : https://doi.org/10.4000/bhce.3222

Este documento fue generado automáticamente el 4 enero 2021.

Bulletin d'histoire contemporaine de l'Espagne 


\title{
Sara HIDALGO GARCÍA DE ORELLÁN, Los resistentes. Relato socialista sobre la violencia de ETA (1984-2011)
}

\author{
Gaizka FERNÁNDEZ SOLDEVILLA
}

\section{REFERENCIA}

Sara HIDALGO GARCÍA DE ORELLÁN, Los resistentes. Relato socialista sobre la violencia de ETA (1984-2011), Bilbao, Ramón Rubial Fundazioa, 2017, 183 p.

1 Ignorada por un creciente sector de la ciudadanía vasca, aislada internacionalmente, cercada por las fuerzas policiales y con su brazo político estrangulado por la Ley de Partidos, el 20 de octubre de 2011 ETA anunció el "cese definitivo de su actividad armada". De tal forma esperaba propiciar "una solución justa y democrática al secular conflicto político". Por descontado, los etarras no se habían acostado violentos para despertarse adalides del civismo y la tolerancia. Su apuesta por los cauces institucionales estaba forzada por la efectividad de la acción policial y judicial. Además, era una opción meramente táctica. Dando la vuelta a la sentencia de Carl von Clausewitz, la banda terrorista contemplaba la política como la continuación de su guerra por otros medios.

Fundada a finales de 1958, el saldo de la larga historia de ETA arroja más de ochocientas víctimas mortales: 853, según el Ministerio del Interior; 845 , según los cálculos de Raúl López Romo $(2015)^{2}$, quien añade un mínimo de 2.533 heridos (de ellos 709 con gran invalidez), 15.649 amenazados (en el período 1968-2001; en 2002 había un millar de personas con escolta) y un número desconocido de exiliados forzosos, extorsionados y damnificados económicamente. A los daños humanos se suman los efectos perniciosos que la violencia ha causado en la ciudadanía: el miedo, la polarización política, el 
sectarismo, el control de no pocos movimientos sociales y culturales por parte del nacionalismo vasco radical, que durante mucho tiempo casi monopolizó la calle, y la persecución sufrida por los partidos no nacionalistas. En definitiva, la degradación de la democracia. Sin embargo, las nuevas generaciones apenas conocen la historia del terrorismo y de sus víctimas. ¿Cómo vamos a recordarla?

3 Tales interrogantes colocan a la sociedad vasca en una compleja encrucijada. Por un lado, nos topamos con la tentación de pasar página sin haberla leído primero. Hacerlo supondría seguir mirando hacia otro lado, actuar como si aquí nunca hubiera ocurrido nada, como si ETA no hubiese existido. El olvido no solo es un escarnio a las víctimas, sino que, además, deja un hueco que probablemente llenaría la propaganda ultranacionalista que pretende justificar a posteriori los crímenes de la banda: el relato del secular "conflicto vasco", cuyo argumento central consiste en que los (invasores) españoles y los (invadidos) vascos llevarían siglos sosteniendo una intermitente guerra étnica de la que ETA sería la última manifestación. Se trata de una construcción narrativa acientífica, que no se apoya en la realidad histórica, sino en la tergiversación interesada, a pesar de lo cual ha conseguido cierta difusión.

4 Tanto la amnesia voluntaria de nuestro pasado (por omisión) como la asunción acrítica del relato del "conflicto vasco" (por acción) implican legitimar los cimientos intelectuales del terrorismo etarra, provocando el riesgo potencial de que la violencia rebrote en el futuro. Los historiadores y los demás científicos sociales podemos hacer algo al respecto: investigar con seriedad, rigor y método, para divulgar los resultados de nuestro trabajo entre la ciudadanía. Al igual que hicieron nuestros homólogos en otras sociedades que habían pasado por un periodo de sufrimiento y violencia, como Alemania tras la II Guerra Mundial, tenemos el deber cívico de propiciar un examen crítico del pasado reciente. El conocimiento es la única vacuna. Como escribió Tertuliano, dejan de odiar los que dejan de ignorar.

5 Sobre ETA y sus víctimas existe una amplia pero desigual bibliografía, en la que encontramos desde literatura de combate a trabajos académicos. En la estela de estos últimos, aunque con un afán divulgativo, se sitúa Los resistentes. Relato socialista sobre la violencia de ETA (1984-2011), de la historiadora Sara Hidalgo, especialista en la historia del socialismo vasco. El libro está dedicado a mostrar las plurales experiencias vitales de los afiliados y dirigentes del PSE-EE, Partido Socialista de Euskadi-Euskadiko Ezkerra, con relación a su estatus de objetivo de los ataques de las diferentes ramas de ETA y de su entorno político, la autodenominada "izquierda abertzale". El eje cronológico recorre casi treinta años: desde 1984, con el asesinato del exconcejal de Rentería Vicente Gajate y el senador Enrique Casas, a 2011, con el "cese" del terrorismo. No obstante, pese a que los Comandos Autónomos Anticapitalistas no utilizaron su militancia en el PSE como justificación del crimen, la autora recuerda que el primer socialista asesinado fue Germán González (octubre de 1979).

6 Se trata de una obra pensada para el público en general, lo cual no desmerece su innegable calidad, que Hidalgo procura demostrar en la primera parte del libro. Y lo hace: el libro cuenta con unos sólidos cimientos intelectuales. Ahora bien, dado el enfoque divulgativo del texto, quizá resulte excesivo dedicar veinte páginas al marco teórico. Resulta muy sugestivo desde el punto de vista académico, pero quizá es poco atractivo, y una dificultad añadida, para el lector medio. En cualquier caso, es una muestra del rigor de la autora, quien se mueve entre las coordenadas de la historia de las emociones y de la historia oral. 
7 Hidalgo realizó 34 entrevistas, una cantidad suficiente para un trabajo de esta naturaleza. Así, ha dado visibilidad a quienes permanecían ocultos de una u otra manera. Es cierto que la memoria siempre es subjetiva, por lo que las fuentes orales han de manejarse con precaución, pero eso es precisamente lo que hace la autora, quien también utiliza fuentes hemerográficas y bibliográficas como complemento de los relatos de vida de sus informantes.

A lo largo de las páginas de esta obra, con las voces de las víctimas como materia prima y la historia del PSE-EE como hilo conductor, la autora consigue tejer un honesto e interesante análisis de la presión, las amenazas, la deshumanización, el chantaje, la indiferencia de un sector de la sociedad y los atentados que durante décadas sufrieron los socialistas vascos, similar a los que padecieron los militantes de otras fuerzas constitucionalistas. También es la historia de la creación de una auténtica cultura de la resistencia, como indica el título. Se trata de una primera aproximación al tema, como subraya Sara Hidalgo, pero Los resistentes es una magnífica síntesis, bien escrita y planteada, promesa de futuros trabajos que vengan a desarrollar completamente las sendas que este ha abierto. En ese sentido, se echa de menos un libro similar sobre los partidos vascos de derecha y centro derecha, como la UCD, Unión de Centro Democrático, o el PP, Partido Popular, que todavía no tienen quien les escriba.

\section{NOTAS}

1. http://www.europapress.es/nacional/noticia-censo-interior-reconoce-10181victimas-terrorismo-cifra-853-asesinados-eta-20170618102154.html

2. Raúl López Romo, Informe Foronda: los efectos del terrorismo en la sociedad vasca (1968-2010), Madrid, Los Libros de la Catarata, 2015.

\section{AUTORES}

\section{GAIZKA FERNÁNDEZ SOLDEVILLA}

Historiador. Centro para la Memoria de las Víctimas del Terrorismo 